\title{
Geometrical size effect in high cycle fatigue strength of heavy-walled Ductile Cast Iron GJS400: Weakest link vs. defect-based approach
}

\author{
Matteo Cova ${ }^{1,2, a}$, Marco Nanni $^{2}$ and Roberto Tovo ${ }^{1}$ \\ ${ }^{1}$ Universita' di Ferrara, Dip. di Ingegneria, via Saragat 1, 44122 Ferrara, Italy \\ ${ }^{2}$ SACMI Imola S.C., via Selice 17/A, 40026 Imola (BO), Italy
}

\begin{abstract}
Fatigue strength is known to decrease with increasing dimension of the component. This is due to a technological size effect, related to the production process, and to a geometrical size effect, due to a higher probability of finding a large defect. To investigate the latter, an heavy-walled component made of Ductile Cast Iron (DCI) has been trepanned and a fatigue test plan has been carried out using 4 different specimen geometries. An attempt has been made to relate the resulting fatigue strength using a weakest-link approach based on the effective volumes and surfaces. This approach seems to work well only in cases of different specimen's lengths. Some of the fracture surfaces were analyzed by means of SEM and the initiating defects were identified and measured. An approach in which the defects population can be randomly distributed in the specimen has been tried. Virtual fatigue tests have been carried out by considering pure propagation of the worst defect. The resulting fatigue curves showed that this approach is promising but needs further description of the initiation phase.
\end{abstract}

\section{Introduction}

It is a well known phenomenon that the fatigue strength of material decreases with increasing the size of the component. In most materials, fatigue initiates from discontinuities, that may be considered as micro-cracks [1]. To investigate the matter, fatigue specimens of 4 different geometries were machined from a component made of Ductile Cast Iron GJS-400 in order to test different volumes and surfaces.

\section{The initiating defects analysis}

Part of the specimens were analyzed by means of optical and S.E. microscope in order to identify and measure the initiating defects. The $\sqrt{\text { area }}$ of the defects were analyzed using the Gumbel distribution for each data set, Fig. 1. It is worth notice that, despite the fact that the material is the same and that the volume/surface is lower, the larger defects are found in the \#047 and \#48 series. In the author's opinion,

\footnotetext{
${ }^{a}$ Corresponding author: matteo. cova@sacmi.it
}

This is an Open Access article distributed under the terms of the Creative Commons Attribution License 4.0, which permits unrestricted use, distribution, and reproduction in any medium, provided the original work is properly cited. 


\section{MATEC Web of Conferences}

Table 1. Fatigue test details. The strengths values have been normalized to the $50^{\text {th }}$ percentile of the fatigue strength of the \#047 serie.

\begin{tabular}{llllllllll}
\hline $\begin{array}{l}\text { Specimen } \\
\text { ID }\end{array}$ & $\begin{array}{l}\text { Gauge } \\
\text { diameter } \\
(\mathrm{mm})\end{array}$ & $\begin{array}{l}\text { Gauge } \\
\text { length } \\
(\mathrm{mm})\end{array}$ & $\begin{array}{l}\text { Relative } \\
\text { Volume }\end{array}$ & $\begin{array}{l}\text { Relative } \\
\text { Area }\end{array}$ & $\begin{array}{l}\text { Fatigue } \\
\text { data } \\
\text { points }\end{array}$ & $\begin{array}{l}\text { Weibull } \\
\text { scale } \\
\text { parameter }\end{array}$ & $\begin{array}{l}\text { Weibull } \\
\text { shape } \\
\text { parameter }\end{array}$ & $\begin{array}{l}\text { Weibull } \\
\text { location } \\
\text { parameter }\end{array}$ & $\begin{array}{l}\text { Median } \\
\text { Fatigue } \\
\text { Strength }\end{array}$ \\
\hline $\mathbf{\# 0 4 8}$ & 10 & 12 & 0.2 & 0.2 & 28 & 1.16 & 17.26 & 0.02 & 1.21 \\
$\mathbf{\# 4 7}$ & 10 & 69 & 1 & 1 & 51 & 0.41 & 7.43 & 0.61 & 1 \\
$\mathbf{\# 0 4 5}$ & 20 & 37 & 2.1 & 1.1 & 36 & 1.16 & 17.26 & 0.02 & 1.15 \\
$\mathbf{\# 0 4 6}$ & 32 & 160 & 21.4 & 10.8 & 24 & 0.83 & 19.45 & 0.15 & 0.96 \\
\hline
\end{tabular}

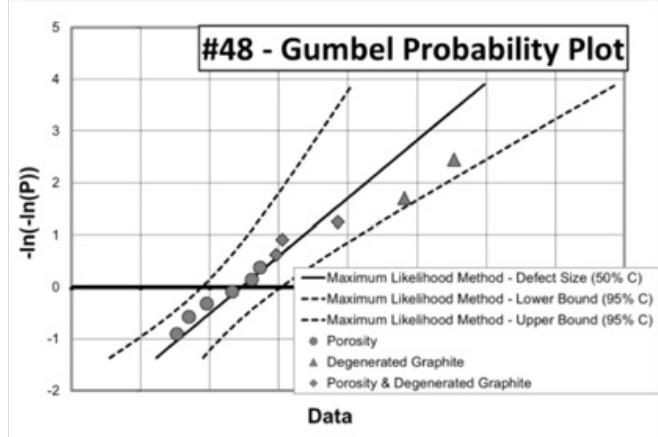

Figure 1. Gumbel plot of the initiating defects for fatigue set \#048.

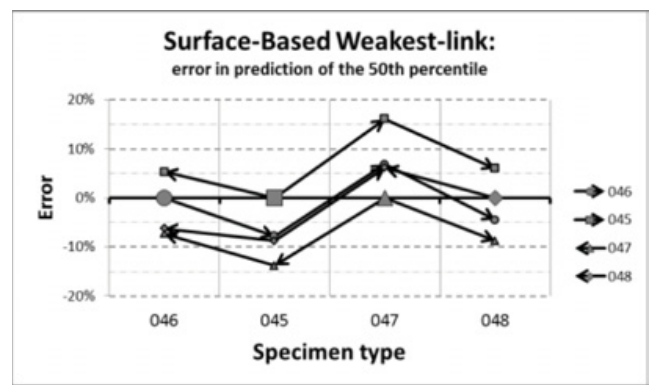

Figure 2. Error in prediction of the median value using weakest-link approach.

this may be related to the diameter playing some role in the initiation phase. Also the larger defects are always agglomerates of degenerated graphite.

\section{Weakest link approach}

In the W-L approach, the component is modeled as a serial system in which failure is defined as any of the link fails. When used in conjuction with the 3-p Weibull distribution for strength, it is possible to derive the $\sigma(P)$ for a different geometry based on the ratio of the effective volume/surface [2].

Figure 2 shows that the prediction is acceptable only within the \#045-\#046 and \#047-\#048. The surface-based weakest link performs slightly better than the volume based one. 


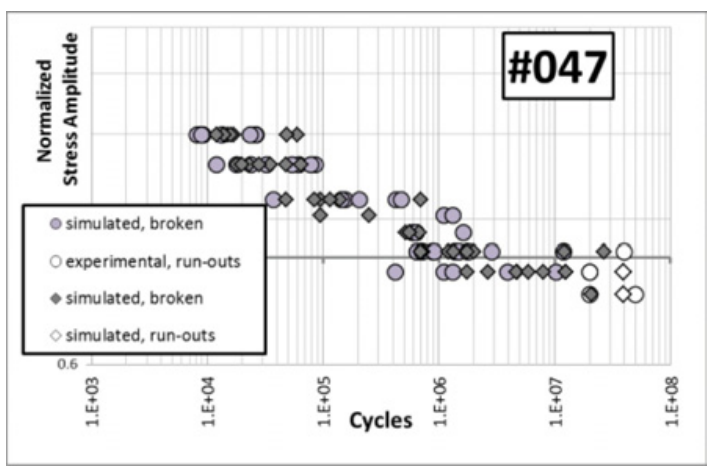

Figure 3. Experimental and Simulated data for specimen \#047.

\section{Explicit defect approach}

The steps of this approach are the following: 1. starting from an appropriate measure campaign, define a probabilistic distribution of defects in terms of dimension, shape and position; 2 . define a failure process (example: defects are treated as cracks and only propagation is considered); 3. perform a Monte Carlo analysis by running $\mathrm{n}$ sets of defect distributions.

The routine written for this work is a simpler version of the P. FAT software [3]. In Fig. 3 it is possible to see that the main features of the experimental data has been captured in the numerical approach.

\section{References}

[1] Murakami Y. Metal Fatigue: Effects of Small Defects and Nonmetallic Inclusions. Elsevier (2002)

[2] Diemar, A et al. Determination of local characteristics for the application of the Weakest-Link model, Mat.-wiss. u. Werkstofftech., 36, No. 5 (2005)

[3] Wormsen A et al. A post-processor for fatigue analysis based on finite element stress field. Comput Meth Applied Mech \& Eng.; v. 197, i. 6-8, p. 834-845 (2008) 